\title{
An unusual cause of school refusal
}

\author{
Zafar Meenai, ${ }_{1}^{1}$ Nupur Sarkar, ${ }^{2}$ Rakesh Biswas ${ }^{3}$ \\ ${ }^{1}$ Department of Pediatrics, People's College of Medical Sciences, Bhopal, India; \\ 2Department of Pediatrics, Peoples College of Medical Science \& Research Center, Bhopal, India; \\ ${ }^{3}$ Department of Medicine, People's College of Medical Sciences, Bhopal, India
}

Correspondence to Professor Rakesh Biswas, rakesh7biswas@gmail.com

\begin{abstract}
Summary
A 6-year-old school boy was brought to the child developmental specialist with complaints of school absenteeism and school refusal behaviour of 7 months duration. Before the onset of school refusal, he had two episodes of unresponsiveness with abnormal posturing preceded by vertigo, which were diagnosed and managed as epileptic seizures. Following these episodes, he started avoiding school due of episodic palpitations, 'nervousness' and sweating. However, the episodes of unresponsiveness did not recur. His symptoms were attributed to stress/ anxiety by both the examining physicians as well as the parents because repeated clinical evaluation including 12-lead ECG done three times and echocardiography were normal. Fortunately the sixth time, the diagnosis was clinched on an ECG when he presented to the paediatrician with tachycardia and hypotension.
\end{abstract}

\section{BACKGROUND}

School absenteeism and refusal behaviour is a significant problem encountered in 1-2\% of school going and $5 \%$ of clinic- referred children. Though it is often due to behavioural and psychiatric disorders, but medical problems which share somatic symptoms with anxiety- based school refusal behaviour need to be kept in mind during clinical evaluation by a pediatrician/physician. But difficulties in diagnosis may arise when the underlying medical condition is rare and the manifestations are episodic as happened in this case, where the episodic symptoms were attributed to a more common childhood disorder and school refusal was assumed by the examining doctors as well as the guardians to be behavioural/psychiatric in origin.

\section{CASE PRESENTATION}

A 6-year-old school boy was brought to the child developmental specialist in a medical college hospital for evaluation of school refusal for the past 7 months.

He was apparently well till 7 months back when he had an episode of vertigo followed by unresponsiveness, frothing from the mouth and extensor spasm of upper limbs and trunk lasting around $90 \mathrm{~s}$ and vomiting once. This was followed by another episode of unresponsiveness and flexor spasm of upper limbs 15 days later. He was taken to the paediatrician. Physical examination was normal. Electroencephalogram (EEG) and CT head were also normal. A provisional diagnosis of epilepsy was made and he was started on sodium valproate in the dose of $15 \mathrm{mg}$ per $\mathrm{kg}$, which the parents stopped 7 days later. Since then, he did not have any further episodes of unresponsiveness; but almost every fortnight he had palpitations and 'feeling nervous' associated with sweating. His symptoms would subside in an hour or two spontaneously. These episodes were not related to exertion, posture or meals. He would refuse to go to school for 3-4 days after the episodes and frequent school absenteeism led to progressively worsening school performance. He was taken to the cardiologist twice, but cardiovascular examination was normal. ECG (done three times) and echocardiography were normal. Thyroid function test (fT3, fT4, thyroid stimulating hormone) was normal. Parents started believing that the child was avoiding school due to anxiety and there were underlying psychosocial reasons or stressors unknown to them. They were advised also by the treating doctors to consult the child developmental specialist.

There was no history of seizures, congenital or acquired heart disease and he was not on any long-term medications. He was born at term by normal vaginal delivery with a birth weight of $3 \mathrm{~kg}$. There were no adverse events in the antenatal and neonatal periods and he was thriving and developing normally. He was performing well in his preschool till 7 months earlier. His parents were first cousins (first degree consanguinity) and he was the only child. There was no family history of seizures, developmental disorders, psychiatric illnesses, ischemic or congenital heart disease, sudden cardiac deaths or hearing defects. Both his parents were high-school educated. Father was a bus-driver by profession and mother was a housewife.

Examination at the clinic revealed a child with normal weight (27 kg>97th percentile), height $(125 \mathrm{~cm}$-at 97 th percentile) and body mass index $\left(17.28 \mathrm{~kg} / \mathrm{m}^{2}\right.$-slightly more than 85th percentile-overweight) for age. He appeared comfortable and had a cheerful disposition. His pulse rate was 88 beats per min, regular, normal volume, respiratory rate was 26 breaths per min and blood pressure (BP) was 100/64 mm Hg right arm supine. There was no pallor, clubbing or oedema. There were no neurocutaneous markers or dysmorphisms. Systemic examination including cardiovascular and nervous systems was unremarkable. A detailed psychological and behavioural assessment was done, but no behavioural or psychiatric disorder was detected. The developmental expert planned for a review including another evaluation by a paediatrician after about a fortnight

However, the parents brought back the child a week later to the development clinic of the hospital after he had 


\section{BMJ Case Reports}

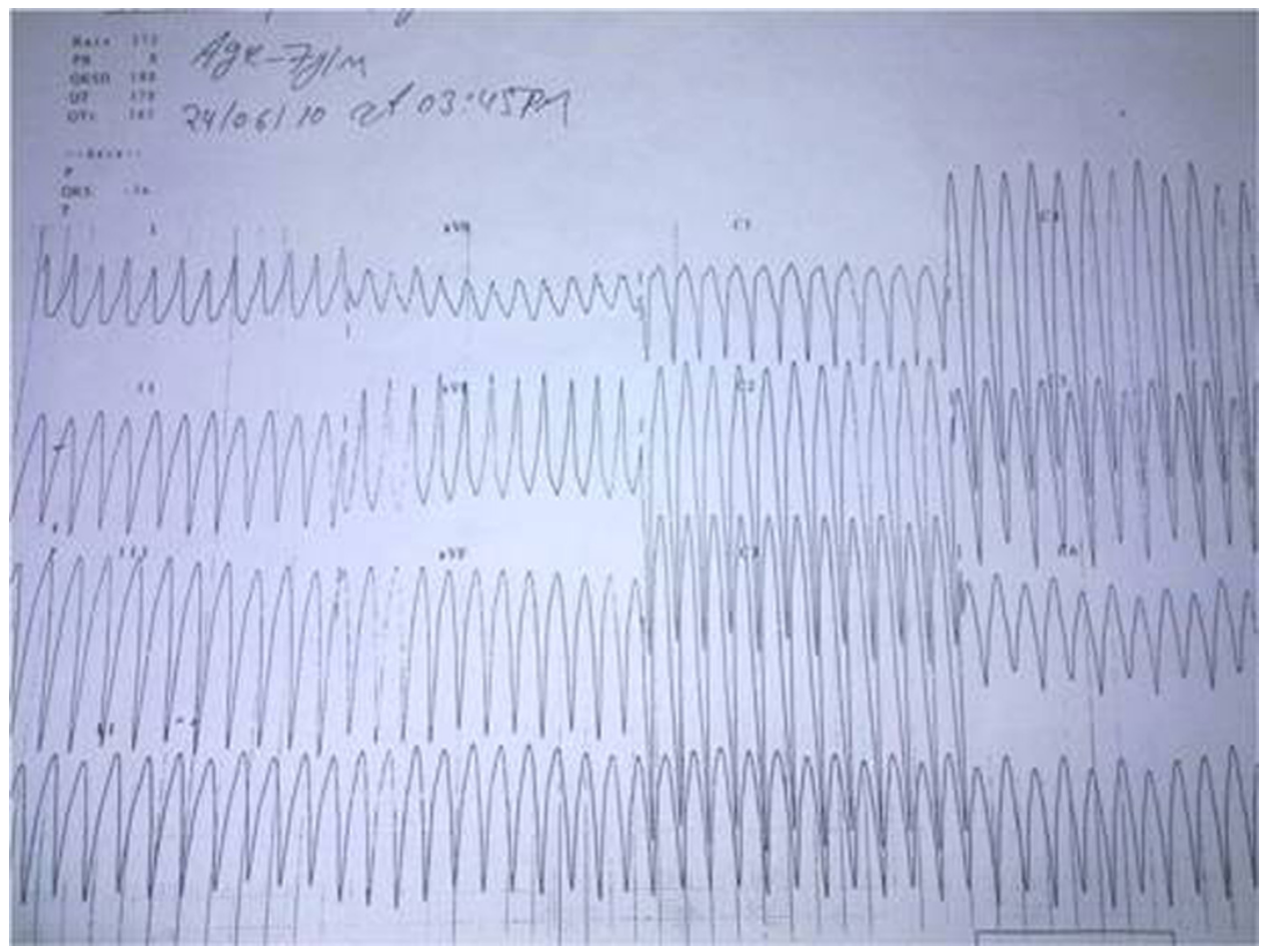

Figure 1 ECG showing monomorphic ventricular tachycardia.

sweating with palpitations lasting about an hour few hours back. He had vomited once and had become transiently unresponsive.

The child was ambulatory, but appeared distressed. His pulse rate was 253 beats per min, regular, but thready, respiratory rate was 34 breaths per min, BP was 80/60 $\mathrm{mm} \mathrm{Hg}$ right arm supine. Extremities were cold and clammy. Pulse oximeter reading was $99 \%$ in room air. Jugular venous pulse could not be assessed. There was no oedema. He was rushed to the emergency section of the cardiac unit, where he was found to have ventricular tachycardia (figure 1). He was resuscitated, direct current shock was given and he reverted to a normal sinus rhythm 15 min after intravenous lignocaine and amiodarone (figure 2).

\section{INVESTIGATIONS}

During the course of his hospital stay, the investigation results were as follows: haemoglobin- $12.4 \mathrm{~g} / \mathrm{dl}$, total leucocyte count-13 300/ 1 l with a normal differential count, platelet count-2 $75000 / \mu 1$, random blood sugar-103 mg/ $\mathrm{dl}$, blood urea-23 $\mathrm{mg} / \mathrm{dl}$, creatinine $-0.68 \mathrm{mg} / \mathrm{dl}$, serum sodium-140 meq/l, potassium-4.01 meq/1, calcium-9.5 $\mathrm{mg} / \mathrm{dl}$, magnesium-2.0 mg/dl. ECHO with Dopplernormal with an ejection fraction of $60 \%$. Surface ECG details- ventricular tachycardia. After antiarrhythmics (lignocaine and amiodarone) were adminintered, heart rate $-75 / \mathrm{min}, \mathrm{PR}$ interval $=140 \mathrm{msec}$, ORS axis of $35^{\circ}$, QTc of $422 \mathrm{~ms}$.

Positron emission tomography scan of the chest was done to look for evidences of myocarditis and it was essentially normal. Cardiac MRI showed a structurally normal heart. The final diagnosis was haemodynamically unstable monomorphic ventricular tachycardia.

\section{DIFFERENTIAL DIAGNOSIS}

1. Ventricular tachycardia leading to convulsive syncope.

2. Epilepsy with ventricular tachycardia.

3. Epilepsy with anxiety related school refusal.

4. Conversion disorder.

\section{TREATMENT}

He was put on daily oral amiodarone, metoprolol, phenytoin and diltiazem as advised by the cardiologist.

\section{OUTCOME AND FOLLOW-UP}

However, the episodes kept on recurring, for which he underwent radiofrequency catheter ablation (RFCA) around 6 weeks later. Unfortunately, RFCA did not make a significant difference to his condition and a repeat RFCA is being planned currently.

\section{DISCUSSION}

School absenteeism and school refusal behaviour is a significant problem encountered by paediatricians/physicians and psychologists and behavioural therapists. It affects $1-2 \%$ of school-aged and $5 \%$ of clinic-referred children. ${ }^{1}$ While school absenteeism has been linked with myriad medical problems notably asthma, headaches, epilepsy, irritable bowel syndrome, haemoglobinopathies/coagulopathies, type I diabetes mellitus etc., somatic complaints are especially common in the youth with anxiety- based absenteeism and refusal behaviour. ${ }^{2}$ These somatic symptoms include headache, abdominal pain, nausea, vomiting, sweating, lightheadedness, palpitations and shortness of breath. ${ }^{2}$ Thus in children with somatic complaints in conjunction with school refusal behaviour, it is important to distinguish between those suffering from a true physical 


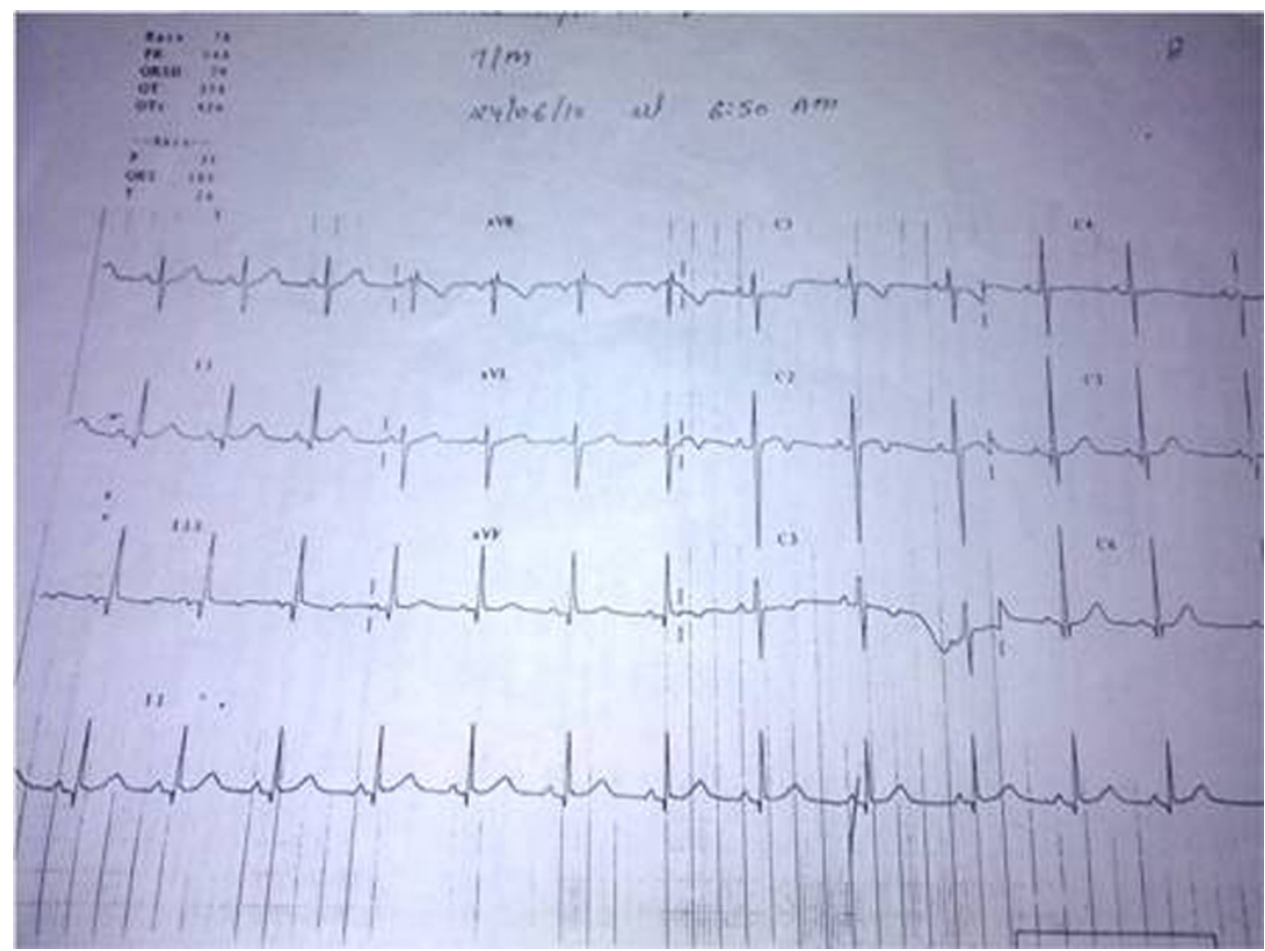

Figure 2 ECG showing normal sinus rhythm.

malady and those who exaggerate actual low-grade physical symptoms that may result from stress. Exaggeration of these symptoms may occur to get attention/sympathy from significant others or to induce parental acquiescence to miss school and stay at home. So a thorough medical examination is important before labeling it as a behavioral or psychiatric problem.

Our patient did have at least five thorough medical check-ups including investigations deemed necessary except a Holter monitoring. But no abnormality could be detected until the sixth time. Palpitations, sweating and vomiting are well-known to be associated with anxiety related school refusal and thus caused delay in arriving at the underlying cause. Moreover, arrhythmia has not been cited as a cause of school refusal in the literature so far, which makes this case unusual.

The other misleading feature was the presence of frothing and abnormal posturing during the episodes of unresponsiveness, which lead to the wrong diagnosis of epilepsy, when he was actually having convulsive syncope. Convulsive syncope-that is, cerebral anoxic seizure activity secondary to transient global impairment of blood flow-can be difficult to differentiate from epilepsy. Interval EEG is not useful for distinguishing between the two, because a single interval EEG may be normal in as many as $50 \%$ of patients with epilepsy. ${ }^{3}$ In experimental studies, where hypoxia was induced by various like Valsava maneuver, ocular compression, bloodletting etc. and film/video recordings were employed, convulsions were observed in the order of $70-90 \%$ of those subjected to cerebral hypoxia. ${ }^{4}$ However, in real life, syncopal convulsions may be overlooked due to their fleeting nature and variable intensity. In clinical case series, convulsions have been witnessed in $5 \%$ to $12 \%$ of patients with vasovagal (neurally-mediated) syncope and in $15 \%$ of patients with various causes of syncope. ${ }^{6} 7$ The convulsions may be myoclonic, tonic (usually non-repetitive unlike in seizures), and sometimes associated with complex movements like chewing, lip smacking and even visual hallucinations. Some workers have mentioned presence of tongue- biting, déjà vu/ jamais vu, head-turning, unresponsiveness, unusual posture, limb movement and amnesia, confusion to be more likely in case of seizures, while lightheadedness, sweating and the spell following prolonged standing or sitting are more predictive of syncope. ${ }^{6} 8$ According to these criteria, our patient fulfilled three features suggestive of seizures, viz. unresponsiveness, unusual posture and limb movement and one feature in favour of syncope, viz. palpitations. Others have suggested that convulsive syncope can be reliably distinguished from epilepsy by the brief duration of the ictal phase, lack of rhythmic clonic movements, rapidity of recovery and absence of post-ictal phenomena ${ }^{9} 10$ but these are insufficiently reliable or specific to be standardised against more stringent diagnostic criteria. However, EEG during both convulsive and nonconvulsive syncope shows generalised slow waves of high amplitude, flattening of the trace rather than seizure-like activity. ${ }^{9}{ }^{11}$ In retrospect, our patient had sweating and palpitations before becoming unresponsive, a brief ictal phase, no clonic movements and rapid recovery with absent postictal phase which point to convulsive syncope rather than epileptic seizures.

To sum up, the initial labeling of convulsive syncope as epileptic seizures and normal physical examination on multiple episodes led to the delay in the diagnosis of the underlying life-threatening condition. Early and accurate diagnosis of convulsive syncope and its differentiation from epileptic seizures is important because cardiac 
rhythm may be affected by anticonvulsant drugs like phenytoin and carbamazepine ${ }^{12}{ }^{13}$; besides, in addition, severe episodic bradycardia and ventricular tachyarrhythmias are potentially life threatening and require urgent cardiological intervention. Approximately $15 \%$ of children and adolescents at the age of 8-18 years experience at least one episode of syncope. ${ }^{14}$ Although syncope in the pediatric age group appears to be an isolated phenomenon with good prognosis, it could also be a manifestation of a lifethreatening disease. Thus, even the first syncope should be evaluated in children. Neurocardiogenic (also known as vasovagal) syncope is the most common (60-80\%). ${ }^{14}$ Cardiogenic syncope is rare $(6 \%)$, although they require special attention due to their background. In another study conducted on children presenting with syncope (age 2-19 years) by McHarg et al, only $6 \%$ of the cases had a cardiac cause of syncope. Two-thirds of children with cardiac syncope had structural abnormalities of the heart like aortic stenosis, hypertrophic cardiomyopathy and other cardiomyopathies, operated congenital heart disease, while the rest had arrhythmias in a structurally normal heart. ${ }^{15}$ The reported 1 year mortality of patients with a cardiac cause of syncope is $18-33 \%{ }^{16-19}$ compared with $3-6 \%$ for syncope of unknown origin. ${ }^{17-19}$ Clues to the presence of cardiac syncope may include acute onset of syncope, frequent episodes, low difference between blood pressure readings in supine and erect positions (after standing for $2 \mathrm{~min}$ ) and abnormal 12 lead ECG. ${ }^{20}$

To sum up, our patient had an uncommon cause of syncope and a rare cause of school refusal.

\section{Learning points}

- A thorough clinical evaluation by a physician is mandatory before attributing school absenteeism and refusal to behavioural or psychiatric disorders.

- Both epileptic seizures and syncope may present with abnormal movements and posturing during the episodes of unresponsiveness; but presence of rhythmic clonic movements points towards epileptic seizures rather than syncope.

- Though syncope is common in childhood and is of neurocardiogenic origin in the majority, cardiac causes need to be suspected if the onset of syncope is acute, and the episodes are frequent and there is a low difference between blood pressure readings in supine and erect positions (after standing for $2 \mathrm{~min}$ ).
Acknowledgements To all who cared for this patient

Competing interests None.

Patient consent Obtained.

\section{REFERENCES}

1. Elliott JG. School refusal: issues of conceptualisation, assessment, and treatment. J Child Psychol Psychiatry 1999;40:1001-12.

2. Kearney CA. School absenteeism and school refusal behavior in youth: a contemporary review. Clin Psychol Rev 2008;28:451-71.

3. Verity $\mathbf{C M}$. The place of the EEG and imaging in the management of seizures. Arch Dis Child 1995;73:557-62.

4. Lempert T, Bauer M, Schmidt D. Syncope: a videometric analysis of 56 episodes of transient cerebral hypoxia. Ann Neurol 1994;36:233-7.

5. Whinnery JE, Whinnery AM. Acceleration-induced loss of consciousness. A review of 500 episodes. Arch Neurol 1990;47:764-76.

6. Sheldon R, Rose $S$, Ritchie D, et al. Historical criteria that distinguish syncope from seizures. J Am Coll Cardiol 2002;40:142-8.

7. Graham LA, Kenny RA. Clinical characteristics of patients with vasovagal reactions presenting as unexplained syncope. Europace 2001;3:141-6.

8. McKeon A, Vaughan C, Delanty N. Seizure versus syncope. Lancet Neurol 2006;5:171-80.

9. Gastaut H, Fischer-Williams M. Electro-encephalographic study of syncope its differentiation from epilepsy. Lancet 1957;273:1018-25.

10. Duvoisin RC. Covulsive syncope induced by the Weber maneuver. Arch Neurol 1962;7:219-26.

11. Aminoff MJ, Scheinman MM, Griffin JC, et al. Electrocerebral accompaniments of syncope associated with malignant ventricular arrhythmias. Ann Intern Med 1988;108:791-6.

12. Boessen $\mathbf{F}$, Anderson EB, Jensen EK, et al. Cardiac conduction disturbances during carbamazepine therapy. Acta Neurol Scand 1983;68:49-52.

13. Beerman B, Edhag O, Vallin H. Advanced heart block aggravated by carbamazepine. Br Heart J 1977;i:754-5.

14. Oko-Lagan J, Kuzma J, Pietrucha B, et al. [Cardiac syncope in children]. Prz Lek 2007;64 Suppl 3:87-91.

15. McHarg ML, Shinnar S, Rascoff H, et al. Syncope in childhood. Pediatr Cardiol 1997; 18:367-71.

16. Kapoor WN. Evaluation and management of the patient with syncope. JAMA 1992;268:2553-60.

17. Silverstein MD, Singer DE, Mulley AG, et al. Patients with syncope admitted to medical intensive care units. JAMA 1982;248:1185-9.

18. Kapoor WN, Karpf M, Wieand S, et al. A prospective evaluation and follow-up of patients with syncope. N Engl J Med 1983;309:197-204.

19. Day SC, Cook EF, Funkenstein H, et al. Evaluation and outcome of emergency room patients with transient loss of consciousness. Am J Med 1982; 73:15-23.

20. Hegazy RA, Lofty WN, Ammar RI, et al. Diagnostic dilemma of cardiac syncope in pediatric patients. Indian Pacing Electrophysiol J 2008;8:22-31. 
This pdf has been created automatically from the final edited text and images.

Copyright 2011 BMJ Publishing Group. All rights reserved. For permission to reuse any of this content visit http://group.bmj.com/group/rights-licensing/permissions.

BMJ Case Report Fellows may re-use this article for personal use and teaching without any further permission.

Please cite this article as follows (you will need to access the article online to obtain the date of publication).

Meenai Z, Sarkar N, Biswas R. An unusual cause of school refusal.

BMJ Case Reports 2011;10.1136/bcr.10.2011.4902, Published XXX

Become a Fellow of BMJ Case Reports today and you can:

- Submit as many cases as you like

Enjoy fast sympathetic peer review and rapid publication of accepted articles

- Access all the published articles

- Re-use any of the published material for personal use and teaching without further permission

For information on Institutional Fellowships contact consortiasales@bmjgroup.com

Visit casereports.bmj.com for more articles like this and to become a Fellow 